\title{
Photographic Facial Soft Tissue Analysis by Means of Linear and Angular Measurements in an Adolescent Persian Population
}

\author{
Vahid Moshkelgosha ${ }^{1,2}$, Sheida Fathinejad ${ }^{3}$, Zeinab Pakizeh $^{2}$, Mohammad Shamsa $^{2}$ and \\ Ali Golkari ${ }^{4, *}$
}

${ }^{I}$ Department of Orthodontics, School of Dentistry, Shiraz University of Medical Sciences, Shiraz, Iran; ${ }^{2}$ Orthodontics Research Center, Shiraz University of Medical Sciences, Shiraz, Iran; ${ }^{3}$ Student's Research Committee, School of Dentistry, Shiraz University of Medical Sciences, Shiraz, Iran; ${ }^{4}$ Department of Dental Public Health, School of Dentistry, Shiraz University of Medical Sciences, Shiraz, Iran

\begin{abstract}
Objective: To obtain objective average measurements of the profile and frontal facial soft tissue to be used as a guide for aesthetic treatment goals. Methods and Materials: This observational study included 110 females and 130 males high school students aged 16-18 years. None of the subjects had any facial deformities. All of them and their parents gave consent to take part in this study. In each case, two standard photographs of profile and frontal views were taken 27 landmarks were digitized on photographs. The mean, standard deviation, and range for a total of 43 facial indices were calculated digitally by computer software. The Student's t-test was used to compare males and females. Results: The ratio between the lower and middle facial thirds was one to one, but the height of the upper facial third was proportionally smaller than the other two-thirds in both sexes. Boys had greater nasal length, depth, and prominence than girls with statistically significant differences. Both upper and lower lips were more prominent in girls than in boys. All measurements of the chin showed sexual dimorphism characterized by greater chin height and prominence and deeper mentolabial sulcus. Boys had greater facial dimensions than girls. Mouth width, nasal base width, and intercanthal distance were significantly greater in boys. Conclusion: The labial, nasal, and chin areas showed sexual dimorphism in most of the parameters used in this study. Boys had larger faces, greater facial heights, longer nasal, labial, and chin lengths, and greater nasal, labial, and chin prominence.
\end{abstract}

Keywords: Aesthetics, face, frontal view, orthodontic photography, orthodontics, profile, soft tissue analysis.

\section{INTRODUCTION}

One of the most important components of orthodontic diagnosis and treatment planning is the evaluation of the patient's facial soft tissue. Since the shape of the human face depends on both the structure of the hard tissue (bone) and the soft tissue that covers it, soft tissue should be analyzed for the correct evaluation of an underlying skeletal discrepancy because of individual differences in soft tissue thickness. The quantitative assessment of the size and shape of the facial soft tissue is widely used in several medical fields such as orthodontics, maxillofacial and plastic surgery, and clinical genetics for diagnosis, treatment planning, and postoperative assessment [1-7]. Obtaining measurements of the facial soft tissue is important in terms of achieving aesthetic criteria [8-11]. With the recent advances in surgical techniques, facial harmony is considered and even incorporated as a treatment goal. The interrelationships of the facial features must be in balance in order to achieve facial harmony.

Analyzing the human face is a science and an art, utilizing both aesthetic and anthropologic tools. Various methods have been used to evaluate facial characteristics, such as

*Address correspondence to this author at the School of Dentistry, Ghomabad, Shiraz, Iran; Tel: +98 9175607254; Fax: +98 7116270325;

E-mail: golkaria@sums.ac.ir anthropometry [12], photogrammetry [13-15], and cephalometry $[16,17]$. The application of photogrammetry in orthodontics was first proposed by Stoner [15], who compared pre- and post-treatment profiles with ideal profiles. Different authors have included soft tissue parameters in photogrammetry, and various facial soft tissue analyses based on standardized photogrammetric method have been described [3, 14, 18-20]. Other photographic methods have also been used to quantify facial aesthetics [21]. Facial soft tissue analysis has been conducted using newer three-dimensional (3D) methods [5, 10, 11, 22], such as laser surface and, more recently, scanning digital 3D photogrammetry [1]. Photogrammetry has been introduced as an alternative to direct measurements to obtain distances between facial landmarks using both two-dimensional and three-dimensional methods. Obtaining measurements from photographs is less intrusive to the patient, more cost-effective, provides a permanent record of the face that can be accessed at a later time, and offers consistency in longitudinal studies in which different observers with different direct measuring techniques might participate [23-25].

The appearance of the face is influenced by age, sex, race, and ethnicity $[3,4,8,26-28]$. Taking ethnic features into consideration as well as changes due to age and sex has been emphasized $[8,9,26]$. It is now apparent that what is considered beautiful and acceptable as the norm for one cul- 
ture may be different for another [9]. Measurements of facial soft tissue have determined normal reference values in different populations, and differences in dentofacial relationships between ethnic and racial groups have been reported. Therefore, it is important to develop standards for the different populations. Furthermore, only a few of the photogrammetric studies conducted on a Persian population has provided norms for adolescents. The aims of the present study were to establish angular and linear photogrammetric norms from standardized photographs of Persian male adolescents and to compare the obtained Persian norms with the norms determined by other investigators of facial aesthetics.

\section{METHODS AND MATERIALS}

\section{Subjects}

The population of this study comprised female and male high school students from Shiraz, Iran. (Shiraz is a mid-sized city located in southern Iran). The age range was 16-18 years. A random sample of 650 individuals was obtained. A brief questionnaire was completed by all individuals that included name, age, origin, medical history, and previous orthodontic treatment history. The study sample was examined clinically by the authors, and 130 boys and 110 girls met the following inclusion criteria: Persian origin, Class I occlusion with minor or no crowding, normal growth and development, all teeth present except third molars, good facial symmetry, no significant medical history, no history of trauma, no previous orthodontic or prosthodontic treatment, and no maxillofacial or plastic surgery. For the purposes of this study, an individual was considered 'Persian' if their parents and grandparents were of Persian origin. The criteria for selection included a pleasing and balanced profile as judged by two of the authors. These two authors had previously calibrated themselves and reached an agreement about the balanced profile using several existing photographs. The subjects were informed of the adopted procedures and gave their consent to the investigation. Data were collected in two stages between June and September of 2013.

\section{Photographic Set-up}

The methods described by Riveiro et al. [3] and Ozdemir et al. [29] were used for the photographic set-up and record taking in profile and frontal views. All subjects were photographed using a standardized technique for profile and frontal views of the face. The photographic set-up consisted of a tripod that held an SLR camera (Canon Eos 400D, Japan) and a primary flash. The tripod controlled the stability and correct height of the camera based on the subject's body height. This ensured the correct horizontal position of the optical axis of the lens (Macro, Sigma, Japan). A $70 \mathrm{~mm}$ focal lens was selected in order to maintain natural proportions. A primary flash was attached to the tripod by a lateral arm at a distance of $27 \mathrm{~cm}$ from the optical axis of the camera and 75 degrees from the upper right angle to avoid the 'red-eye effect' in photographs. Two auxiliary flashes synchronized with the main flash were also used to illuminate the subject's face and reduce unwanted shadows. Another set-up element was a secondary flash placed behind the subject to light the background and eliminate undesirable shadows from the contours of the facial profile. A slave cell al- lowed synchronization with the main flash. A vertical mirror $(20 \times 35 \mathrm{~cm})$ was placed $150 \mathrm{~cm}$ in front of the subject to help with orientation during profile view photography.

\section{Record-taking}

The camera was used in its manual position; the shutter speed was $1 / 125$ per second, and the opening of the diaphragm was f/11. All subjects were photographed using a standardized technique for profile and frontal views of the face. The records were taken in NHP. For recording the profile view, each subject was shown where to stand and asked to relax. Then the subject was instructed to take a few steps, stand relaxed behind a line marked on the floor facing a mirror, and look into his or her own eyes in the mirror with their arms placed at their side. The vertical mirror was outside the frame, approximately $150 \mathrm{~cm}$ from the subject. Subjects were asked to keep their lips relaxed, adopting the position their lips normally show during the day. During frontal photography, each subject stood $2 \mathrm{~m}$ from the camera, and the visual axis was parallel to the floor of the room. Standardized facial photographs were obtained: eyes fully open, no smile, and lips gently closed. Eyewear was removed, and the operator ensured that the patient's forehead, neck, and ears were clearly visible. The digital photos were stored after being recorded on external memory for further processing.

\section{Landmarks and Measurements}

27 landmarks were identified and registered on the frontal and profile pictures of each subject. The landmarks used in this study were selected in accordance with previous studies $[3,4,6,29]$ on the basis that they should be readily visible, reproducible and available for use in analysis, and should be minimally altered by facial makeup. The landmarks are shown in Fig. (1) and definitions for each landmark in this study are shown in Table $\mathbf{1}$.

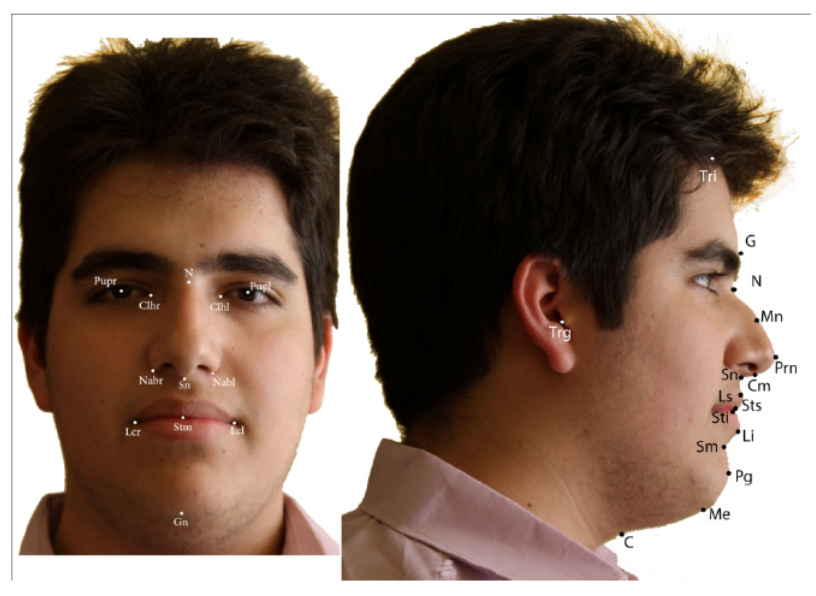

Fig. (1). Soft tissue landmarks used in measurements.

The five reference lines used in the analysis were: TV (sTV-Itv) for which inferior and superior points automatically generated on monitor display, TH (Trg-Ort) that was perpendicular to TV through Trg, TV in $\mathrm{N}$ (N-Ort) that was parallel to TV through N, canut line (Juanita Line), and SnSm. Then 43 facial variables that are defined below were measured. 
Table 1. Anthropometric landmarks used in this study and their definition.

\begin{tabular}{|c|c|}
\hline Landmarks & Definition \\
\hline Trichion (Tri) & $\begin{array}{l}\text { the sagittal midpoint of the forehead that borders } \\
\text { the hairline }\end{array}$ \\
\hline Glabella (G) & $\begin{array}{l}\text { the most anterior point of the middle line of the } \\
\text { forehead }\end{array}$ \\
\hline Nasion $(\mathrm{N})$ & the point in the middle line located at the nasal root \\
\hline Pronasal (Prn) & the most prominent point of the tip of the nose \\
\hline Midnasal (Mn) & $\begin{array}{l}\text { the middle point on the outer contour of the nose } \\
\text { between the pronasal and nasion points }\end{array}$ \\
\hline Columella $(\mathrm{Cm})$ & the most inferior and anterior point of the nose \\
\hline Subnasal (Sn) & the point where the upper lip joins the columella \\
\hline Labial superior (Ls) & $\begin{array}{l}\text { the point that indicates the mucocutaneous limit of } \\
\text { the upper lip }\end{array}$ \\
\hline $\begin{array}{l}\text { Stomion superior } \\
\text { (Sts) }\end{array}$ & the most inferior point of the upper lip \\
\hline $\begin{array}{l}\text { Stomion inferior } \\
\text { (Sti) }\end{array}$ & the most superior point of the lower lip \\
\hline Labial inferior $(\mathrm{Li})$ & $\begin{array}{l}\text { the point that indicates the mucocutaneous limit of } \\
\text { the lower lip }\end{array}$ \\
\hline Supramental (Sm) & the deepest point of the inferior sublabial concavity \\
\hline Pogonion $(\mathrm{Pg})$ & the most anterior point of the chin \\
\hline Menton (Me) & $\begin{array}{l}\text { the most inferior point of the inferior edge of the } \\
\text { chin }\end{array}$ \\
\hline Cervical (C) & the point at the junction of neck and throat borders \\
\hline Tragus (Trg) & the most posterior point of the auricular tragus \\
\hline Alar (Al) & the most lateral point of the alar contour of the nose \\
\hline Ort & the point joining the $\mathrm{TV}$ and the $\mathrm{TH}$ \\
\hline Left canthus (Cthl) & the entocanthion of the left eye \\
\hline Right canthus (Cthr) & the entocanthion of the right eye \\
\hline $\begin{array}{l}\text { Left lip commissure } \\
\text { (Lcl) }\end{array}$ & $\begin{array}{l}\text { the point where the lips join together at the left side } \\
\text { of the mouth }\end{array}$ \\
\hline $\begin{array}{l}\text { Right lip commis- } \\
\text { sure (Lcr) }\end{array}$ & $\begin{array}{l}\text { the point where the lips join together at the right } \\
\text { side of the mouth }\end{array}$ \\
\hline Left alar base (Albl) & $\begin{array}{l}\text { the point on the lower margin of the left alar base } \\
\text { where the ala disappears into the upper lip skin }\end{array}$ \\
\hline $\begin{array}{l}\text { Right alar base } \\
\text { (Albr) }\end{array}$ & $\begin{array}{l}\text { the point on the lower margin of the right alar base } \\
\text { where the ala disappears into the upper lip skin }\end{array}$ \\
\hline Left pupil (Pupl) & the center point of the left eye pupil \\
\hline Right pupil (Pupr) & the center point of the right eye pupil \\
\hline Stomion (Stm) & $\begin{array}{l}\text { the midpoint of the labial fissure when the lips are } \\
\text { closed naturally }\end{array}$ \\
\hline
\end{tabular}

The following eleven vertical linear measurements (parallel to TV) were used (Fig. 2): superior facial third (Tri-G), middle facial third (G-Sn), inferior facial third (Sn-Me), nasal length (N-Sn), length of upper lip (Sn-Sts), interlabial gap (Sts-Sti), length of lower lip (Sti-Sm), vermilion of upper lip (Ls-Sts), vermilion of lower lip (Li-Sti), height of chin (Sm-Me), and height of nasal tip (Sn-Prn).

Twelve linear horizontal measurements (parallel to $\mathrm{TH}$ ) were used in this study: facial depth (Trg-Sn), nasal depth (Al-Prn), nasal prominence (Prn to N-Ort line), subnasal depth (Sn to N-Ort line), mentolabial depth (Sm to N-Ort line), prominence of upper lip (Ls to N-Ort line), prominence of lower lip ( $\mathrm{Li}$ to N-Ort line), prominence of chin (Pg to NOrt line), Canut's nasal prominence (Prn to $\mathrm{Sn}-\mathrm{Sm}$ ), Canut's prominence of upper lip (Ls to Sn-Sm), Canut's prominence of lower lip ( $\mathrm{Li}$ to $\mathrm{Sn}-\mathrm{Sm})$ and Canut's prominence of pogonion (Pg to Sn-Sm) (Fig. 2).

The eight linear measurements and ratios used on the frontal views were: intercanthal distance (Cthr-Cthl), pupil midface distance (Pupr-Pupl), nasal base width (Albr-Albl), mouth width (Lcr-Lcl), lower face-face height $(\mathrm{Sn}-\mathrm{Gn} / \mathrm{N}$ $\mathrm{Gn}$ ), mandible-face height (Stm-Gn/N-Gn), mandible-upper face height (Stm-Gn/N-Stm), and mandible-lower face height (Stm-Gn/Sn-Gn) (Fig. 2).

Also the twelve angular measurements of the analysis (clockwise) were: nasofrontal angle (N-G-Prn), vertical nasal angle $(\mathrm{N}-\mathrm{Prn} / \mathrm{N}-\mathrm{Ort})$, nasolabial angle $(\mathrm{Cm}-\mathrm{Sn}-\mathrm{Ls})$, mentolabial angle ( $\mathrm{Li}-\mathrm{Sm}-\mathrm{Pg})$, nasal angle $(\mathrm{Sn}-\mathrm{Cm} / \mathrm{N}-\mathrm{Prn})$, angle of the nasal dorsum ( $\mathrm{N}-\mathrm{Mn}-\mathrm{Prn})$, cervicomental angle ( $\mathrm{G}-\mathrm{Pg} / \mathrm{C}-\mathrm{Me})$, angle of the medium facial third (N-Trg-Sn), angle of the inferior facial third ( $\mathrm{Sn}-\mathrm{Trg}-\mathrm{Me})$, angle of the head position ( $\mathrm{Trg}-\mathrm{Ort} / \mathrm{Sn}-\mathrm{Sm})$, angle of facial convexity (G-Sn-Pg) and angle of total facial convexity (G-Prn-Pg) (Fig. 3).

\section{Digitalization}

The photographic records were digitized and analyzed using the Aesthetic Analyzer (Mehrvarzan Giti, Tehran, IRAN) software program for the Windows operating system. The program was previously customized with the landmarks used in this investigation. The methods used in landmark point registration and calibration of computer measurements were reported in the author's previous article [30].

\section{Analysis}

The software calculated all measurements once they were identified on each landmark record (Fig. 4) which had previously been digitized and scaled to life-size. All manual procedures were undertaken by the same operator.

Descriptive statistics (mean, minimum, maximum and standard deviation) for each measurement were computed. The Student's $\mathrm{t}$-test was used to compare males and females. The validity and accuracy of the computer-generated linear and angular measurements were determined by comparing these measurements with their corresponding measurements taken manually on subjects' records and the results were published recently [30]. The reliability of the measurements was examined on the records of all 250 subjects by the same examiner repeating the point marking and digitizing 


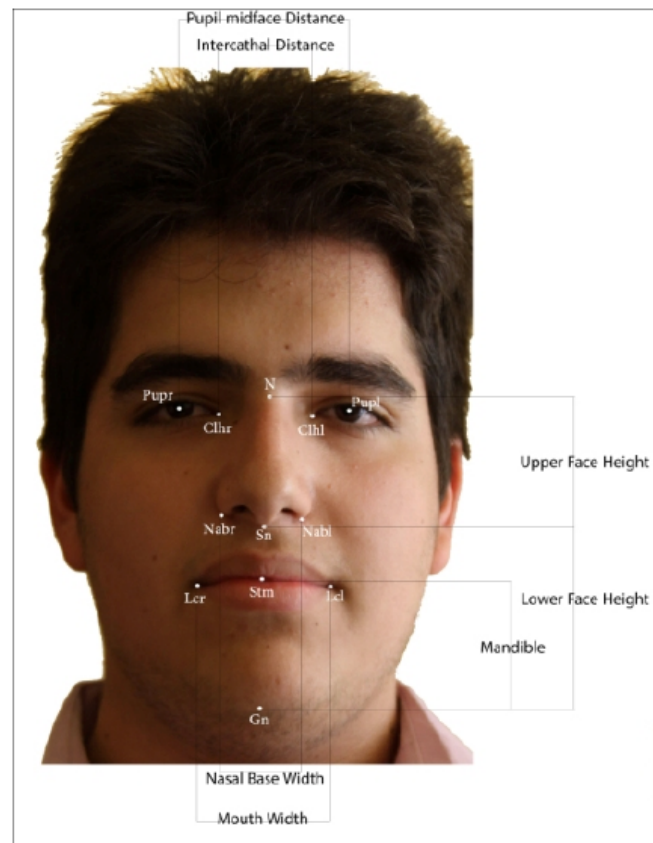

Fig. (2). Linear horizontal and vertical measurements used in study.

procedures after a 4-week interval. The reliability of the method was analyzed using the formula proposed by Dahlberg [31].

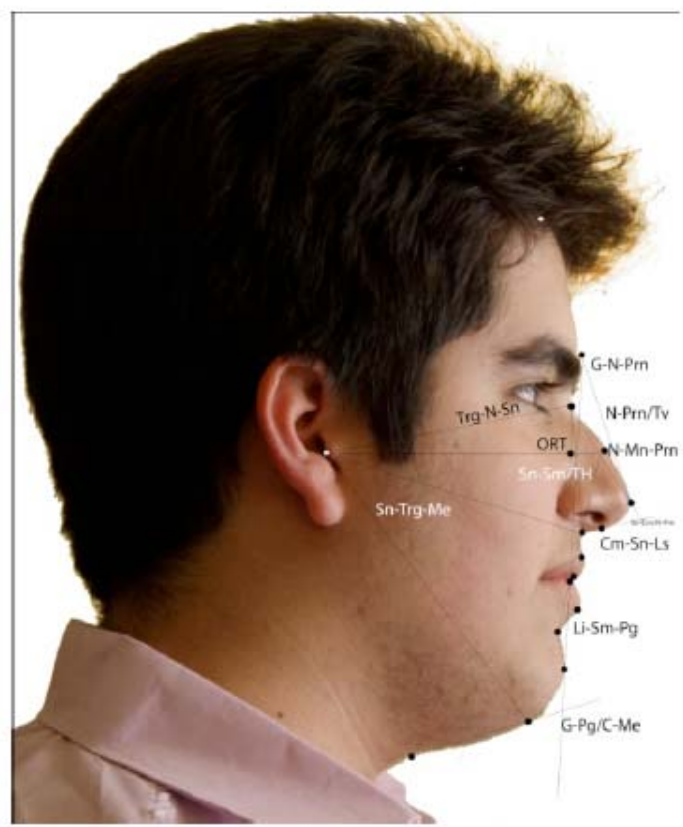

Fig. (3). Angular measurements.

\section{RESULTS}

650 subjects comprised the sample. From them, 510 individuals did not fulfill the requirements (presence of dental and craniofacial malocclusions, previous orthodontic treatment received, origin other than Persian) and were excluded from the study. Descriptive statistics for boys and girls is shown in Table $\mathbf{2}$. The ratio between the inferior and middle facial thirds was one to one in boys and girls, but compara-

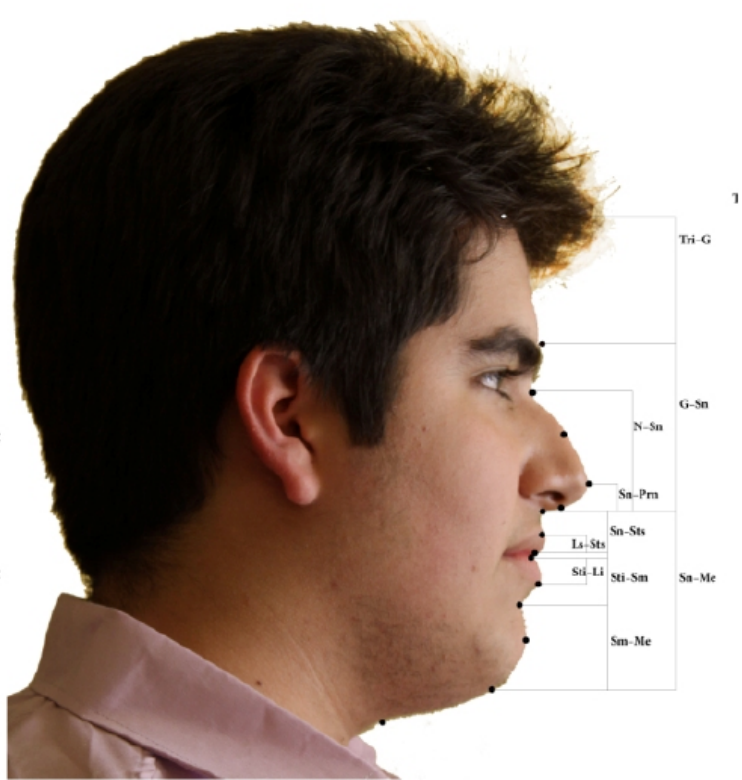

tively, the height of the upper facial third was proportionally smaller in both sexes. The girls had a greater upper facial third height than the boys (boys $=44.4 \pm 4.3 \mathrm{~mm}$ and girls $=$ $49.4 \pm 5.4 \mathrm{~mm} ; \mathrm{p}<0.01)$.

Most nasal measurements showed sexual dimorphism. Boys had greater nasal length, depth, and prominence than girls, with statistically significant differences. $(\mathrm{N}-\mathrm{Sn}$ : boys $=$ $50.5 \pm 2.8 \mathrm{~mm}$; girls $=48 \pm 3.5 \mathrm{~mm} ;$ Prn/TV: boys $=23.1 \pm$ $3.1 \mathrm{~mm}$; girls $=21.5 \pm 2.6 \mathrm{~mm}$; al-Prn: boys $=27.3 \pm 2.8$ $\mathrm{mm}$; girls $=24.7 \pm 2.1 \mathrm{~mm} ; \mathrm{p}<0.01)$. Some measurements, however, showed no difference between sex groups, like the height of the nasal tip and sub nasal depth. (Sn-Prn: boys = $11.8 \pm 1.5 \mathrm{~mm}$; girls $=11 \pm 1.5 \mathrm{~mm}$ )

A greater prominence of upper and lower lip was observed more in girls than in boys $(\mathrm{P}<0.01)(\mathrm{Ls} / \mathrm{TV}$ : boys $=$ $6.5 \pm 4.1 \mathrm{~mm}$; girls $=8.9 \pm 3.1 \mathrm{~mm} ; \mathrm{Li} / \mathrm{TV}$ : boys $=3.45 \pm 3$ $\mathrm{mm}$; girls $=5.4 \pm 3.5 \mathrm{~mm}$ ). The lengths of both upper and lower lips were larger in boys (Sn-Sts: boys $=21.4 \pm 2.6$ $\mathrm{mm}$; girls $=19 \pm 2 \mathrm{~mm}$; Sti-Sm: boys $=18.7 \pm 2.2 \mathrm{~mm}$; girls $=16 \pm 1.5 \mathrm{~mm}$ ). The upper lip length was larger than that of the lower lip, but the vermilion length was larger in the lower lip both in both boys and girls.

All measurements in the area of the chin showed sexual dimorphism characterized by a greater chin height (Sm-Me: boys $=27.7 \pm 3.3 \mathrm{~mm}$; girls $=25.4 \pm 2.2 \mathrm{~mm} ; \mathrm{p}<0.01)$, greater chin prominence $(\mathrm{Pg}-\mathrm{TV}$ : boys $=3.3 \pm 5.3 \mathrm{~mm}$; girls $=1.1 \pm 4.4 \mathrm{~mm} ; \mathrm{Pg} / \mathrm{Sn}-\mathrm{Sm}$ : boys $=6.8 \pm 1.9 \mathrm{~mm}$; girls $=4.6$ $\pm 1.3 \mathrm{~mm} ; \mathrm{p}<0.01$ ), and deeper mentolabial sulcus (Sm-TV: boys $=4.3 \pm 4.8$; girls $=0.7 \pm 4.3 \mathrm{~mm} ; \mathrm{p}<0.01)$ in the boys than in the girls.

In frontal measurements, it was observed that the boys had larger facial dimensions than the girls. Mouth width and nasal base width were significantly higher in boys (Lcr-Lcl: boys $=50.1 \pm 4 \mathrm{~mm}$; girls $=47.9 \pm 3.9 \mathrm{~mm}$; Albr-Albl: boys $=35.3 \pm 3.3 \mathrm{~mm}$; girls $=33.6 \pm 2.1 \mathrm{~mm} ; \mathrm{p}<0.01$ ). 


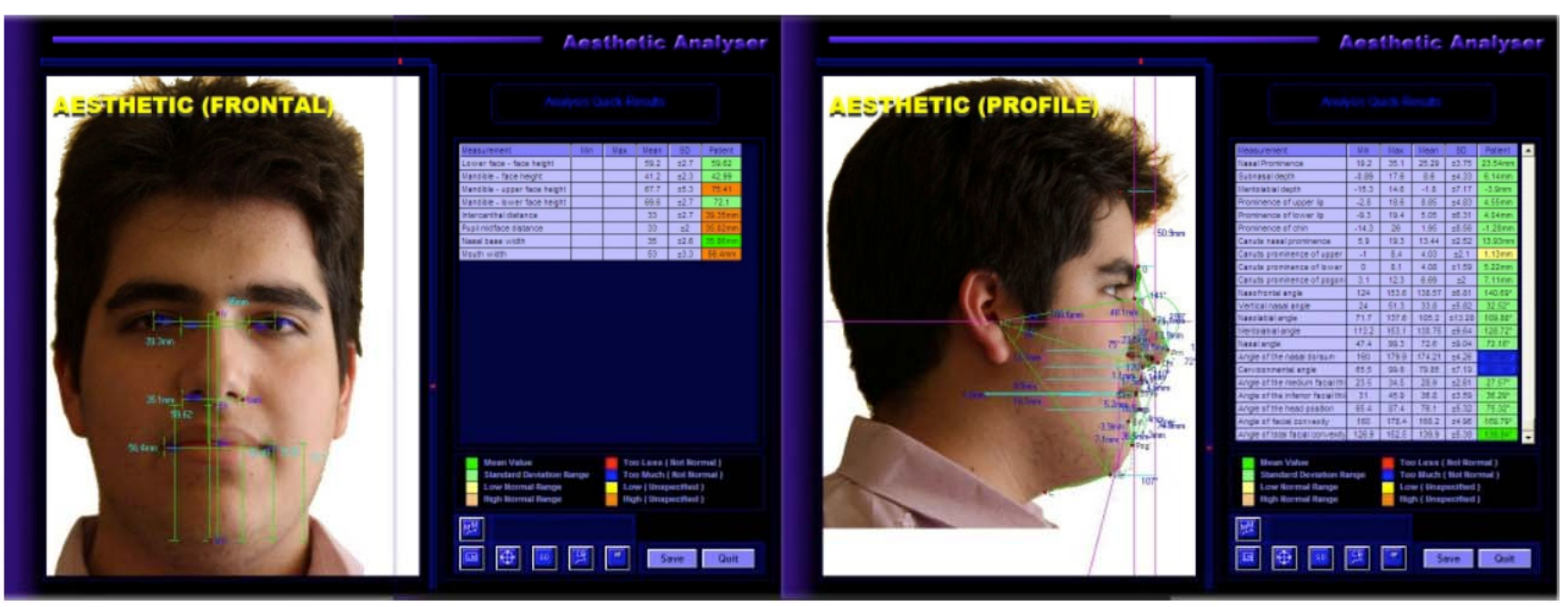

Fig. (4). Linear and angular measurements table and tracing with Aesthetic Analyser software.

Table 2. Measured values of linear and angular measurements.

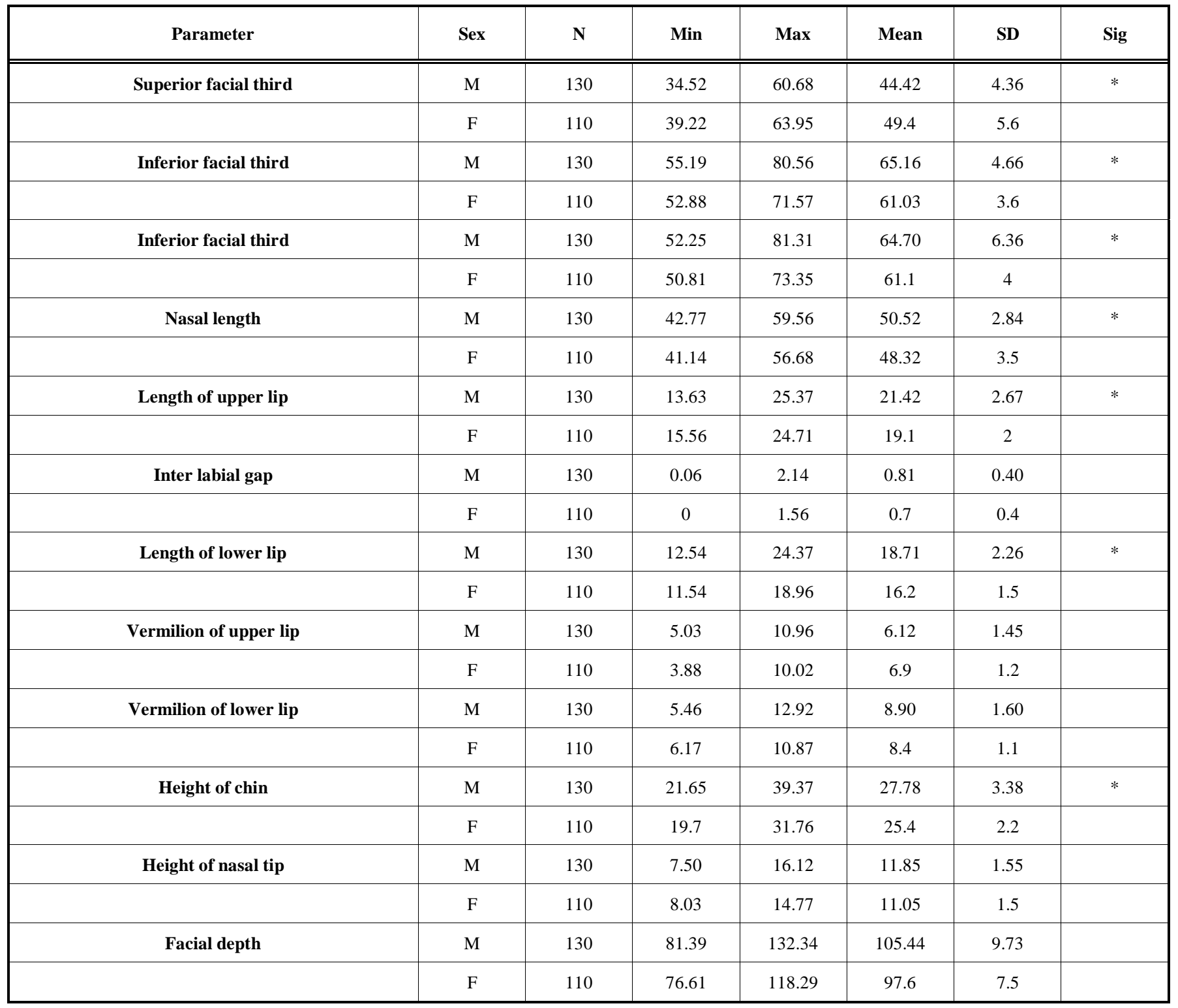


(Table 2) contd....

\begin{tabular}{|c|c|c|c|c|c|c|c|}
\hline Nasal depth & M & 130 & 22.43 & 36.49 & 27.35 & 2.86 & $*$ \\
\hline \multirow[t]{2}{*}{ Nasal prominence } & $\mathrm{M}$ & 130 & 16.03 & 31.92 & 22.19 & 3.17 & $*$ \\
\hline & $\mathrm{F}$ & 110 & 15.07 & 27.91 & 21.5 & 2.6 & \\
\hline Sub nasal depth & $\mathrm{F}$ & 110 & 0 & 16.31 & 8.1 & 2.9 & \\
\hline \multirow[t]{2}{*}{ Mentolabial depth } & $\mathrm{M}$ & 130 & -17.25 & 12.13 & -4.31 & 4.80 & $*$ \\
\hline & $\mathrm{F}$ & 110 & -11.54 & 7.8 & -0.7 & 4.3 & \\
\hline Prominence of lower lip & $\mathrm{F}$ & 110 & -2.88 & 11.6 & 5.4 & 3.5 & \\
\hline \multirow[t]{2}{*}{ Prominence of chin } & $\mathrm{M}$ & 130 & -14.72 & 25.49 & 2.30 & 5.39 & $*$ \\
\hline & $\mathrm{F}$ & 110 & -10.3 & 10.17 & 1.1 & 4.4 & \\
\hline \multirow[t]{2}{*}{ Canut's nasal prominence } & M & 130 & 5.85 & 17.43 & 11.35 & 2.12 & \\
\hline & $\mathrm{F}$ & 110 & 6.5 & 13.7 & 10.4 & 1.4 & \\
\hline \multirow[t]{2}{*}{ Canut's prominence of upper lip } & $\mathrm{M}$ & 130 & -1.37 & 7.54 & 3.79 & 1.64 & \\
\hline & $\mathrm{F}$ & 110 & 0.98 & 6.21 & 3.7 & 1.2 & \\
\hline Lower face - face height & $\mathrm{F}$ & 110 & 52.01 & 62.19 & 56.9 & 2.1 & \\
\hline \multirow[t]{2}{*}{ Mandible - face height } & M & 130 & 31.18 & 44.59 & 37.66 & 2.37 & \\
\hline & $\mathrm{F}$ & 110 & 33.89 & 42.25 & 38.3 & 1.5 & \\
\hline \multirow[t]{2}{*}{ Mandible - upper face height } & M & 130 & 45.31 & 80.48 & 60.63 & 6.07 & \\
\hline & $\mathrm{F}$ & 110 & 51.27 & 73.17 & 62.1 & 4.1 & \\
\hline \multirow[t]{2}{*}{ Mandible - lower face height } & M & 130 & 58.95 & 74.09 & 67.56 & 2.51 & \\
\hline & $\mathrm{F}$ & 110 & 61.81 & 72.35 & 67.3 & 2 & \\
\hline \multirow[t]{2}{*}{ Intercanthal distance } & M & 130 & 21.86 & 44.52 & 32.35 & 3.2 & \\
\hline & $\mathrm{F}$ & 110 & 25.69 & 37.11 & 31.4 & 2.5 & \\
\hline \multirow[t]{2}{*}{ Pupil midface distance } & M & 130 & 25.93 & 36.94 & 31.47 & 2.01 & \\
\hline & $\mathrm{F}$ & 110 & 26.16 & 34.48 & 29.6 & 1.6 & \\
\hline \multirow[t]{2}{*}{ Nasal base width } & M & 130 & 23.07 & 41.82 & 35.39 & 3.32 & $*$ \\
\hline & $\mathrm{F}$ & 110 & 29.27 & 39.86 & 33.6 & 2.1 & \\
\hline \multirow[t]{2}{*}{ Mouth width } & M & 130 & 40.37 & 61.52 & 50.17 & 4.01 & * \\
\hline & $\mathrm{F}$ & 110 & 39.73 & 57.1 & 47.9 & 3.9 & \\
\hline
\end{tabular}


(Table 2) contd....

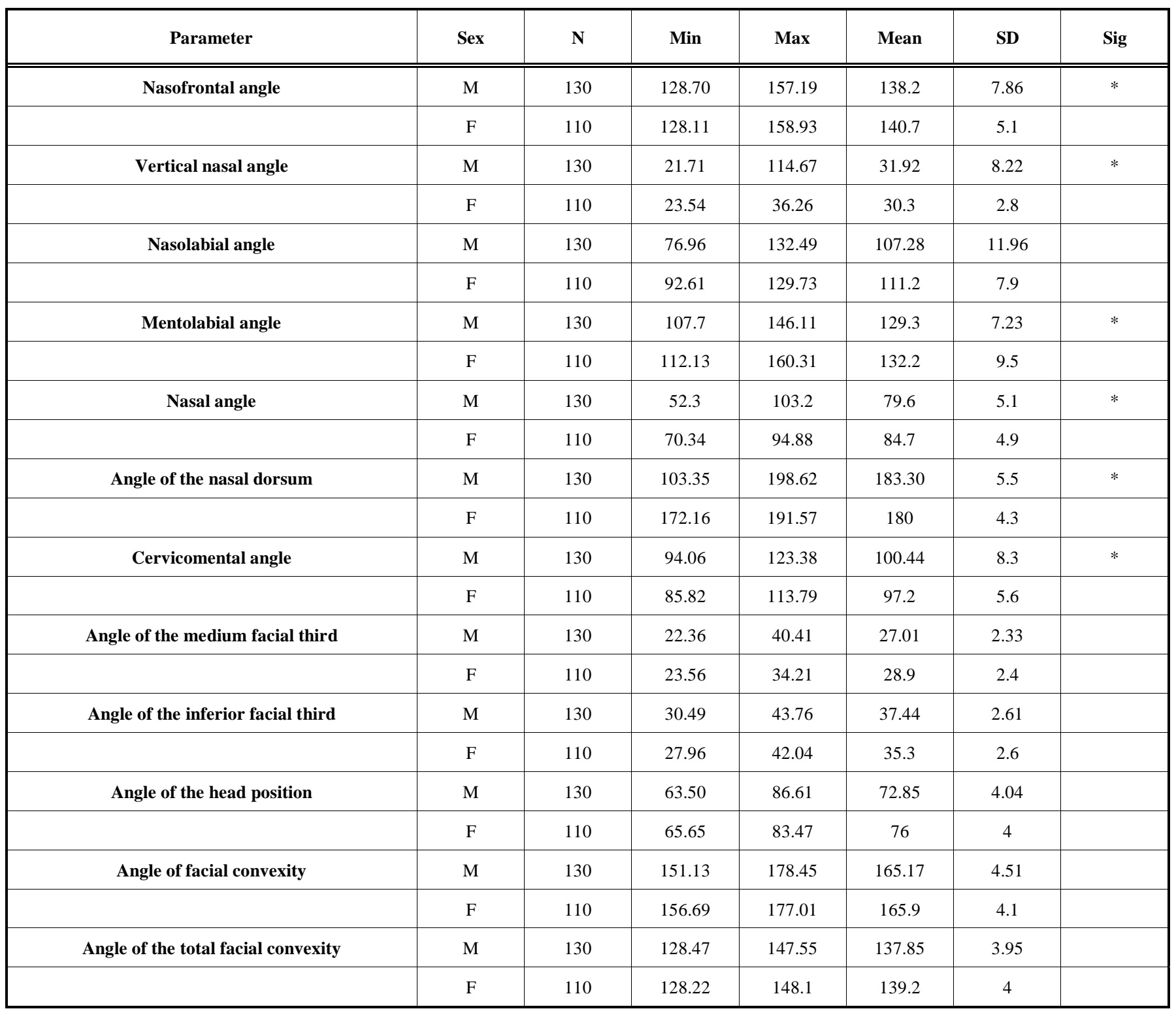

The nasolabial angle $(\mathrm{Cm}-\mathrm{Sn}-\mathrm{Ls})$ showed large variability. It varied from 76.9 to 132.4 degrees in boys and from 92.6 to 129.7 degrees in girls. A wider nasofrontal angle was found in girls (140.7 \pm 5 degrees) compared to boys (138.2 \pm 7.8 degrees; $\mathrm{p}<0.05)$. The mentolabial angle was also significantly wider in girls (boys $=129.3 \pm 7$ degrees; girls $=$ $132.2 \pm 9.5$ degrees; $\mathrm{P}<0.05)$. Nasal angle $(\mathrm{Sn}-\mathrm{Cm} / \mathrm{N}-\mathrm{Prn}$ : girls $=84.7 \pm 4.9$ degrees; boys $=79.6 \pm 5$ degrees) was also wider in girls. In contrast, the cervicomental angle was more acute in girls than in boys $(\mathrm{C}-\mathrm{Me} / \mathrm{G}-\mathrm{Pg}$ : boys $=100.4 \pm 11.2$ degrees; girls $=97.2 \pm 5.6$ degrees; $\mathrm{P}<0.01)$. The rest of the angles that presented sexual dimorphism were larger in boys, including the vertical nasal angle $(\mathrm{N}-\mathrm{Prn} / \mathrm{TV}$ : boys $=34.3 \pm$ 4 degrees; girls $=30.3 \pm 3.8$ degrees) and the nasal dorsum angle $(\mathrm{N}-\mathrm{Mn}-\mathrm{Prn}$ : boys $=183.3 \pm 5.5$ degrees; girls $=180 \pm$ 4.3 degrees).

The results of the method error assessment are shown in Table 3. The greatest variability was found in the nasolabial and mentolabial angles with high standard deviations and large confidence intervals. These angles also showed the highest method error rate (2.56 degrees). The angle of the nasal dorsum also showed a significantly high error rate (2 degrees). The maximum amount of error in linear measurements was $2.25 \mathrm{~mm}$ in the facial depth measurement.

\section{DISCUSSION}

The main goal of this study was to obtain average parameters that define the facial soft tissue characteristics of an adolescent Persian population. Our purpose was twofold: first, to compare facial characteristics of Persian boys and girls, and secondly, to compare the defined facial parameters with those of other races. We compared landmark distances and angles obtained in our study with those of other studies using mean and standard deviation. When comparing the results of this investigation with other studies, the characteristics of the method and the sample used should be considered. 
Table 3. Method error in linear and angular measurements according to Dalhberg's Formula.

\begin{tabular}{|c|c|}
\hline Parameters & Method Error \\
\hline Superior facial third & 1.4141 \\
\hline Middle facial third & 0.8475 \\
\hline Inferior facial third & 1.1517 \\
\hline Nasal length & 0.9925 \\
\hline Length of upper lip & 0.5292 \\
\hline Interlabial gap & 0.1 \\
\hline Length of lower lip & 0.3873 \\
\hline Vermilion of upper lip & 0.3536 \\
\hline Vermilion of lower lip & 0.2646 \\
\hline Height of chin & 0.8944 \\
\hline Height of nasal tip & 0.3317 \\
\hline Facial depth & 2.2583 \\
\hline Nasal depth & 0.866 \\
\hline Nasal Prominence & 0.781 \\
\hline Subnasal depth & 0.9849 \\
\hline Mentolabial depth & 1.2981 \\
\hline Prominence of upper lip & 1.0464 \\
\hline Prominence of lower lip & 1.1597 \\
\hline Prominence of chin & 1.3638 \\
\hline Canut's nasal prominence & 0.4637 \\
\hline Canut's prominence of upper lip & 0.4243 \\
\hline Canut's prominence of lower lip & 0.3317 \\
\hline Canut's prominence of pogonion & 0.3082 \\
\hline Nasofrontal angle & 1.253 \\
\hline Vertical nasal angle & 0.7842 \\
\hline Nasolabial angle & 2.5652 \\
\hline Mentolabial angle & 2.0555 \\
\hline Nasal angle & 1.4509 \\
\hline Angle of the nasal dorsum & 2.0075 \\
\hline Cerviconmental angle & 1.3454 \\
\hline Angle of the medium facial third & 0.495 \\
\hline Angle of the inferior facial third & 0.6671 \\
\hline Angle of the head position & 1.084 \\
\hline Angle of facial convexity & 1.2 \\
\hline Angle of total facial convexity & 0.7681 \\
\hline Lower face - face height & 0.5196 \\
\hline
\end{tabular}

\begin{tabular}{|c|c|}
\hline Mandible - face height & 0.5 \\
\hline Mandible - upper face height & 1.3115 \\
\hline Mandible - lower face height & 0.6364 \\
\hline Intercanthal distance & 0.6245 \\
\hline Pupil midface distance & 0.2739 \\
\hline Nasal base width & 0.5916 \\
\hline Mouth width & 0.946 \\
\hline
\end{tabular}

In the study of facial heights, we found a 1:1 ratio between the inferior facial third and the middle facial third, similar to the findings of Riveiro et al. [3] and Powell [32]. However, some authors found that the inferior third was slightly larger than the middle third. Using a profilometric analysis based on standardized cephalograms and photographs, Peck [20] analyzed vertical height by means of angles such as the total vertical, nasal, maxillary, and mandibular angles and found that the inferior third was larger than the middle third. Epker [18] also reported that the linear lower face height of Caucasian subjects was larger $(38 \%)$ than the upper face height $(32 \%)$ in relation to total face height. Overall, the absolute values were relatively larger in boys than in girls, and more similarity existed between the facial thirds in boys; this corroborates the findings of other authors [3, 6]. Farkas [33] also reported differences between the sexes in which heights were larger in males. Our findings shows that Persian adolescents have a larger superior facial third than European adolescents [3, 6]; however, the middle and inferior thirds were relatively smaller. In other words, Persian boys and girls have higher foreheads than some European races $[3,6]$. In the superior third, sexual dimorphism was found in our study where girls had taller foreheads than boys. We also found that facial depth was significantly larger in boys than in girls. Nanda [34] reported the same significant sexual differences in facial depth. The great individual variability with high standard deviations (SDs) and the difficulty of measuring the Trg and the Tri points should be mentioned. This was reflected in the high rate of method error at the facial superior height and facial depth. The nasofrontal angle showed statistically significant sexual differences in our sample. The girls had a wider nasofrontal angle than the boys, which means the girls have foreheads that are relatively more posteriorly inclined than the boys who have straighter foreheads. Riveiro et al. [3], Milosevic et al. [6], and Malkoc et al. [35] have reported similar findings in different European races. In a study of Caucasians undertaken on frontal and lateral facial views, however, Epker [18] observed no sexual differences in this angle. Girls presented with a more acute cervicomental angle than boys in our study. Malkoc et al.'s [35] findings among Anatolian Turks are similar to our data, but in Hispanics the opposite findings were reported in the work of Riveiro et al. [3] in which the angle was more acute in boys. The absolute values were also smaller in Hispanics than in Persians and Turks.

In the current study, the lower profile orientation was analyzed by the angle of the head position (the Sn-Sm line and the true horizontal). It was observed that wider angles indicated a tendency to prognathic and lower angles to ret- 
rognathic profiles. This angle provided information similar to that of the facial angle used by Peck and Peck [18] and Burstone [36] in total facial contour. Sexual dimorphism was not found. Likewise, Riveiro et al. [4] and Malkoc [35] reported the same results.

In the work of Arnett and Bergman [19], the G-Sn-Pg angle was used to assess the convexity/concavity of profiles. According to the authors, a Class I profile presented an angle range of 165-175 degrees, a Class II profile less than 165 degrees, and a Class III greater than 175 degrees. In the present investigation, the facial convexity and total facial convexity angles obtained were similar in boys and girls. Following the classification of Arnett and Bergman [19], the Class I profiles in the present sample were between 162 and 179 degrees. Riveiro et al. [4] and Malkoc et al. [35] proposed the angle of 162-172 for their class I sample, which is close to that used in our study. Yuen and Hiranaka [37] also reported no sexual dimorphism in their Asian adolescent sample on photographic record.

The findings of our study showed that Persian boys have bigger noses than Persian girls. This was reflected in the greater nasal length, depth, and prominence in boys compared to girls. The subnasal point was also more prominent in boys; however, sexual dimorphism was not evident in all nasal-related measurements. Some parameters, like the height of the nasal tip, did not show sexual variations. This coincides with the findings reported in the studies of Riveiro et al. [3] and Nanda et al. [34]. Significant differences in nasal measurements between Persian adolescents (especially girls) and some European races were evident [3]. The nose is shorter in length, nasal depth is shallower, and subnasal depth is larger in Persians. Overall, Persians seems to have smaller noses. This corresponds with the findings of Fariaby [2] on another Iranian race in which the reported nose dimensions were similar to those of our study. There was less variability in nasal related measurements than in facial parameters discussed earlier, as was the case with the error rate, which ranged from 0.3 to $0.8 \mathrm{~mm}$. The great variability of subnasal depth measurements obtained using the TV should be considered in analyzing the results. In addition to linear measurements, different angles were used to describe the nose morphology in this study. The vertical nasal angle and the nasal dorsum angle were wider in boys than in girls. The nasal angle also shows sexual dimorphism (wider in girls). The results of this study are similar to the findings of Riveiro et al. [4], but different from Malkoc et al. [35], who did not find considerable gender differences in these angles. McNamara et al. [38] found sexual differences in the nasal tip angle in their study on adult Caucasians, yet this angle did not differ between the sexes in our study nor in that of Riveiro et al. [4] or Malkoc et al. [35]. The relationship between the nasal base (columella) and the upper lip, analyzed by the nasolabial angle, is a facial profile parameter that has broader clinical uncertainty. In the present sample, this angle showed great variability and method error rate. For these reasons, the results of this measurement should be interpreted with caution. The nasolabial angle measured in our Persian sample was higher in both boys and girls than those reported in previously published studies of other races $[4,6$, 35], but similar to the findings of Fariaby et al. [2] in a different Iranian sample. Because the lips are also more promi- nent in Persians, this wide angle is the result of nose position. Burstone [36] reported a smaller nasolabial angle in a Caucasian adolescent sample with a normal facial appearance. Yuen and Hiranaka [37] in a study on Asian adolescents reported a more acute nasolabial angle than that of our study. McNamara et al. [38] also reported similar results in a study on lateral cephalograms of adult Caucasians with pleasing faces.

The labial area should be thoroughly evaluated, because the appearance of the lips and the smile can be modified by orthodontic treatment. The lengths of both lips were larger in boys than in girls. Other studies, like those of Riveiro et al. [3], Park and Burstone [39], and Yuen and Hiranaka [37], also found a larger length of the upper lip in boys. Although sexual differences in lower lip length were verified by Riveiro et al. [3], other researchers did not find significant differences (Park and Burstone [39], Yuen and Hiranaka [37]). The absolute amount of upper and lower lip lengths in the current Persian sample were similar to the findings of Fariaby [2] and Yuen and Hiranaka [37] who both studied Asian samples, but were smaller than those reported by Riveiro et al. [3] in their study of Hispanics. In the current study, the interlabial gap was not significantly different between boys and girls. This finding is in contrast to those of Riveiro et al. [3]. Moreover, the amount of interlabial gap in this study was smaller than what Legan and Burstone [40] and Bishara et al. [41] reported in their studies [2.5 to 3 $\mathrm{mm}]$. The differences can be related to varied lip resting positions in different studies. The length of the vermilion did not show sexual differences as in the works of Riveiro $\mathrm{et} \mathrm{al}$. [3] and Bishara et al. [41], but the inferior vermilion (Li-Sti) was $1.5 \mathrm{~mm}$ larger than the superior one (Ls-Sts). The same findings were reported in other studies $[3,6]$. The absolute amount of vermilion in this study was smaller than that in the Riveiro et al. study of Hispanics [3]. The prominence of the upper and lower lips was larger in girls than in boys in our study, regarding either the Sn-Sm line or TV as a reference. In both cases, the upper lip was more forward than the lower one. This finding contrasts those of Riveiro et al. [3] in that the protrusions of the lips were different regarding different reference lines. This could possibly be explained by the different NHP in boys and girls. In the current study, the NHP was not significantly different between boys and girls as shown by the similar angle of the head position in both sexes.

Sexual differences are evident in all measurements related to the chin in this study; in the other words, Persian boys have greater chin size than Persian girls. Riveiro et al. [3] obtained the same result in their study, however, other investigators, like Park and Burstone [40], did not find any differences between males and females in their analysis of chin height. Compared to the findings of Riveiro et al. [3] on Hispanics, our findings show that Persians have a similar chin height, but its prominence is greater (with regard to TV) in both boys and girls. The sexual difference in the mentolabial sulcus is also greater in Persians. The measurements relative to the TV showed great variability in the current study and other similar studies $[3,4,6,35]$ and should be interpreted with caution. The other measurement that should be evaluated with caution because of its large variability and high error rate is the mentolabial angle. A more acute angle 
in a male is indicative of a larger depth of the mentolabial sulcus and a more protruding chin point. These findings are similar to those of McNamara et al. [38] and Lines et al. [42].

In the frontal analysis, it was evident that facial dimensions are larger in boys than in girls. Boys have larger nasal base width, larger mouth, and more separated eyes than girls. The findings of Fariaby et al. [2] are supportive of our data. The mean result of nasal width in our study is smaller than that of Korean [1] and African-American [8] noses. The nasal widths of Turkish [29] and white Northern Italians [5] were similar to our results. Compared to Caucasians, Persians have a smaller mouth width, but a larger nasal width. The intercanthal distance is similar between the two races, while the interpupil distance is shorter in Persians which is more indicative of a rounded eye compared to the Caucasians.

We recognized that some factors might limit the findings of our study. We couldn't eliminate all factors that may influence the facial appearance such as body mass index (BMI) in selection of our subjects because of difficulty in obtaining enough samples. In addition, the selection of subjects in this study was based on the clinical evaluation and no radiographic records were used because of ethical issues. This could limit the strength of diagnostic criteria's used in this study. a selection process that involves different levels of diagnosis with a larger board of clinicians and non clinicians(i.e. lay persons, artists, students and ...) may be a better idea.

\section{CONCLUSION}

The soft tissue values obtained from this sample can be used as standards in comparisons of subjects with the same ethnic characteristics, a dental Class I occlusion, and good soft tissue profile. Therefore, the values can be used for the comparison of subjects with malocclusions, indicating areas of facial disharmony. Persians had more prominent lips with less length, smaller and shorter noses, more obtuse nasolabial angles, and more prominent chins compared to Hispanics. In frontal views, Persians had flatter noses and smaller mouths with more rounded eyes. The labial, nasal, and chin areas showed sexual dimorphism in most of the parameters used in this study. Boys had larger faces in general, with greater facial heights, longer nasal, labial, and chin lengths, greater nasal, labial, and chin prominence, and a greater nasal and facial depth in the tragus point. In facial heights, a proportion of $1: 1$ between the middle and the inferior facial thirds was observed. In the height of the vermilions, sexual dimorphism was not observed. Gender differences were observed in the nasofrontal, mentolabial, cervicomental, and most nasal related angles. Another important finding was the high method error rate and large variability of the nasolabial and mentolabial angles.

\section{CONFLICT OF INTEREST}

The authors confirm that this article content has no conflict of interest.

\section{ACKNOWLEDGEMENTS}

This paper is extracted from S. Fathinejad's DDS thesis which was undertaken under supervision of V. Moshkel- gosha and advisory of A. Golkari. The study was approved, registered and financially supported by the International Branch of Shiraz University of Medical Sciences.

\section{REFERENCES}

[1] Baik HS, Jeon JM, Lee HJ. Facial soft-tissue analysis of Korean adults with normal occlusion using a 3-dimensional laser scanner. Am J Orthod Dentofacial Orthop 2007; 131: 759-66.

[2] Fariaby J, Hossini A, Saffari E. Photographic analysis of faces of 20-year-old students in Iran. Br J Oral Maxillofac Surg 2006; 44 : 393-406.

[3] Ferna'ndez-Riveiro P, Sua'rez-Quintanilla D, Smyth-Chamosa E, Sua'rez-Cunqueiro M. Linear photogrammetric analysis of the soft tissue facial profile. Am J Orthod Dentofacial Orthop 2002; 122: 59-66.

[4] Ferna'ndez-Riveiro P, Smyth-Chamosa E, Sua'rez-Quintanilla D, Sua'rez-Cunqueiro M. Angular photogrammetric analysis of the soft tissue facial profile. Eur J Orthod 2003; 25: 393-9.

[5] Ferrario VF, Sforza C, Serrao G. A three-dimensional quantitative analysis of lips in normal young adults. Cleft Palate Craniofac J 2000; 37: 48-54.

[6] Milosevic' SA, Varga ML, Slaj M. Analysis of the soft tissue facial profile of Croatians using of linear measurements. J Craniofac Surg 2008; 19: 251-8.

[7] Nagle E, Teibe U, Kapoka D. Craniofacial anthropometry in a group of healthy Latvian residents. Acta Med Lituanica 2005; 12: 47-53.

[8] Porter JP, Olson KL. Anthropometric facial analysis of the African American woman. Arch Facial Plast Surg 2001; 3: 191-7.

[9] Choe KS, Sclafani AP, Litner JA, Yu GP, Romo T. $3^{\text {rd }}$ ed. The Korean American woman's face: anthropometric measurements and quantitative analysis of facial aesthetics. Arch Facial Plast Surg 2004; 6: 244-52.

[10] Sforza C, Laino A, D'Alessio R, et al. Three-dimensional facial morphometry of attractive Italian women. Prog Orthod 2007; 8: 282-93.

[11] Sforza C, Laino A, D’Alessio R, Grandi G, Tartaglia GM, Ferrario VF. Soft-tissue facial characteristics of attractive and normal adolescent boys and girls. Angle Orthod 2008; 78: 799-807.

[12] Farkas LG. Anthropometry of the head and face in medicine. New York: Elsevier North Holland Inc 1981; p. 285.

[13] Gavan JA, Washburn SL, Lewis PH. Photography: an anthropometric tool. Am J Phys Anthropol 1952: 10: 331-51.

[14] Neger MA. A quantitative method for the evaluation of the soft tissue facial profile. Am J Orthod 1959; 45: 738-51.

[15] Stoner MM. A photometric analysis of the facial profile. Am J Orthod 1955; 41: 453-69.

[16] Garner LD. Soft tissue changes concurrent with orthodontic tooth movement. Am J Orthod 1974; 66: 367-77.

[17] Roos N. Soft tissue changes in Class II treatment. Am J Orthod 1977; 72: 165-75.

[18] Epker BN. Adjunctive esthetic surgery in the orthognathic surgery patient. In: McNamara JA, Carlson D S, Ferrara A, Ed. Esthetics and the treatment of facial form. Michigan: Center for Human Growth and Development, University of Ann Arbor 1992; p. 187.

[19] Arnett GW, Bergman RT. Facial keys to orthodontic diagnosis and treatment planning - part I. Am J Orthod Dentofacial Orthop 1993; 103: 299-312.

[20] Peck H, Peck S. A concept of facial esthetics. Angle Orthodontist 1970; 40: 284-318.

[21] Peerlings RHJ, Kuijpers-Jagtman AM, Hoeksma JB. A photographic scale to measure facial aesthetics. Eur J Orthod 1995; 17: 101-9.

[22] Aung SC, Foo CL, Lee ST. Three dimensional laser scan assessment of the Oriental nose with a new classification of Oriental nasal types. Br J Plast Surg 2000; 53: 109-6.

[23] Douglas TS. Image processing for craniofacial landmark identification and measurement: a review of photogrammetry and cephalometry. Comput Med Imag Graph 2004; 28: 401-9.

[24] Guyot L, Dubuc M, Richard O, Philip N, Dutour O. Comparison between direct clinical and digital photogrammetric measurements in patients with 22q11 microdeletion. Int J Oral Maxillofac Surg 2003; 32: 246-52. 
[25] Zhang X, Hans MG, Graham G, Kirchner HL, Redline S. Correlations between cephalometric and facial photographic measurements of craniofacial form. Am J Orthod Dentofacial Orthop 2007; 131: 67-71.

[26] Bozkir MG, Karakas P, Oguz O. Vertical and horizontal neoclassical facial canons in Turkish young adults. Surg Radiol Anat 2004; 26: 212-9.

[27] Farkas LG, Katic MJ, Forrest CR, et al. International anthropometric study of facial morphology in various ethnic groups/races. J Craniofacial Surg 2005; 16: 615-46.

[28] Porter JP. The average African American male face: an anthropometric analysis. Arch Facial Plast Surg 2004; 6:78-81.

[29] Ozdemir ST, Sigirli D, Ercan I, Cankur S. Photographic facial soft tissue analysis of healthy turkish young adults: anthropometric measurements. Aesth Plast Surg 2009; 33:175-84.

[30] Moshkelgosha V, Shamsa M. Introduction of Aesthetic Analyser software: computer-aided linear and angular analysis of facial profile photographs. J Dent Shiraz Univ Med Sci 2012; 13: 59-63.

[31] Dahlberg G. Statistical methods for medical and biological students. New York: Interscience Publications 1940

[32] Powell N, Humphreys B. Proportions of the esthetic face. In: Smith JD, Ed. New York: Thieme-Stratten 1984; p.72.

[33] Farkas LG, Hreczko TA, Kolar JC, Munro IR, Chir B. Vertical and horizontal proportions of the face in young adult North American Caucasians: Revision of Neoclassical canons. Plast Reconstr Surg $1985 ; 75: 328-37$.
[34] Nanda RS, Ghosh J. Armonı́a y crecimiento de los tejidos blandos faciales en eltratamiento ortodóncico. Semin Ortod 1995; 1: 3-17.

[35] Malkoç S, Demir A, Uysal T, Canbuldu NF. Angular photogrammetric analysis of the soft tissue facial profile of Turkish adults. Eur J Orthod 2009; 31:174-9.

[36] Burstone CJ. The integumental profile. Am J Orthod 1958; 44: 125.

[37] Yuen SWH, Hiranaka DK. A photographic study of the facial profiles of southern Chinese adolescents. Quintessence Int 1989; 20: 665-76.

[38] McNamara JA, Brust EW, Riolo ML. Soft tissue evaluation of individuals with an ideal occlusion and well-balanced face. In: McNamara JA, Carlson DS, Ferrara A, Eds. Aesthetics and the treatment of facial form. Michigan: Center for Human Growth and Development, University of Ann Arbor 1992; pp. 115-46.

[39] Park YC, Burstone CJ. Soft tissue profile. Fallacies of hard-tissue standards in treatment planning. Am J Orthod Dentofacial Orthop 1986; 90: 52-62.

[40] Legan HL, Burstone CJ. Soft tissue cephalometric analysis for orthognathic surgery. J Oral Surg 1980; 38: 744-51.

[41] Bishara SE, Jacobsen JR, Hession TJ, Treder JE. Soft tissue profile changes from 5 to 45 years of age. Am J Orthod Dentofacial Orthop 1998; 114: 698-706.

[42] Lines PA, Lines RR, Lines CA. Profilemetrics and facial esthetics. Am J Orthod 1978; 73: 648-57.

Received: March 12, 2015

Revised: April 13, 2015

Accepted: May 02, 2015

(C) Moshkelgosha et al.; Licensee Bentham Open.

This is an open access article licensed under the terms of the Creative Commons Attribution Non-Commercial License (http://creativecommons.org/licenses/by-nc/3.0/) which permits unrestricted, non-commercial use, distribution and reproduction in any medium, provided the work is properly cited. 